\title{
An Analysis of Policy Satisfaction Using the Expectancy Disconfirmation Model*
}

\author{
Soonae Park** and Dukyun Hwang***
}

\begin{abstract}
This study analyzed the impact of people's expectations on policy satisfaction in South Korea, using an expectancy disconfirmation model wherein service satisfaction is decided by expectation and performance. Though recent studies have applied the model to evaluations of specific public services, this study applied it to macro policies in South Korea. To measure expectation levels, proxy variables were used: people's trust in participants who have influence on policy and in the policy-making process. The results were not compatible with the model: the model's implication that higher expectations induce lower satisfaction did not fit macro policy cases, where high expectations had a significant positive influence on satisfaction. Moreover, the type of expectation that is the focus of marketing studies, predictive expectation, is not appropriate to use with public policy cases; the quantity of prior experiences as a basis of predictive expectation is not significant to policy satisfaction. Expectation is obviously an important factor in the public's evaluation of policy outputs, but further studies are necessary to fully understand its role.
\end{abstract}

Keywords: expectancy disconfirmation model, expectation, satisfaction, macro policy.

* This study used the same data as a prior study, The Impact of Social Capital on Satisfaction with National Policy (Park and Hwang 2009). Although both papers investigate antecedents explaining policy satisfaction, theoretical frames and approaches are different. While the prior study focused on respondents' universal trust levels based on social capital theory, this study treated particular trust levels focusing on primary actors in policy processes based on the expectancy disconfirmation model.

** Associate Professor, Graduate School of Public Administration, Seoul National University, psoonae@snu.ac.kr

*** Doctoral Student, The Maxine Goodman Levin College of Urban Affairs, Cleveland State University, dukyunh@gmail.com

Manuscript received October 9, 2010; out for review October 21, 2010; review completed November 16, 2010; accepted November 26, 2010.

The Korean Journal of Policy Studies, Vol. 25, No. 3 (2010), pp. 47-67.

(C) 2010 by the GSPA, Seoul National University 


\section{INTRODUCTION}

Why do some people consider a glass to be half empty while others opine that the same glass is half full? According to the expectancy disconfirmation theory, one reason for this difference in satisfaction levels is the difference in expectation levels. Someone who expected more water in the glass may think that the amount is insufficient, while someone who expected less water may consider the amount sufficient. The purpose of this study was to apply this logic to the evaluation of public policies and to see whether expectation has a significant impact on policy satisfaction.

This study differed in three ways from previous studies of the impact of expectations on public services. First, it focuses on macro policies in South Korea, while prior studies focused on concrete local services like trash disposal, police, schools, advisory services to small and medium-sized companies, and water supply (Deichmann and Lall 2003; Roch and Poister 2006; Bennett 2007; Kleyn, Rothmann, and Jackson 2007). Local services are influenced by local organizational characteristics and conditions, so study results are hard to generalize. Second, most studies have focused on the results and outputs of their target services, with a view to analyzing their performance; performance - in such studies - is not measured objectively but perceived subjectively. The problem with using a subjective measure of service quality is that it confuses concept with satisfaction. This study instead focuses on macro policies as performances that are given to all people and measured relatively objectively. This does not mean that it is useless to study performance, but that it can be controlled to investigate the impact of expectation on macro policy satisfaction. Third, this study investigated whether previous experience with public services is a significant factor in satisfaction.

There are three kinds of expectation: predictive expectation what a person thinks will happen based on prior experience, normative expectation what a person thinks should happen, and ideal expectation what a person wants to happen. In this study, the expectancy disconfirmation model, wherein service satisfaction is decided by expectation and performance, was applied to macro policies focusing on normative expectation. To measure the expectation, a proxy was used: trust in policy participants and trust in the policy process. Policy participants were divided into political actors, administrators, and the nonprofit sector.

This article first reviews the expectancy disconfirmation model and then introduces the essential concept of expectation, including its three types. After explaining the appropriation of trust as a proxy for normative expectation, it discusses two hypotheses tested by the study: (1) the quantity of prior experience with public services is significant to the level of satisfaction with policy; and (2) expectation based on the proxy variables of trust in policy participants and trust in the policy process is significant to policy satisfaction. 


\section{THEORETICAL BACKGROUND AND PREVIOUS RESEARCH}

\section{Expectancy Disconfirmation Model}

Consumers form judgments regarding services and products using their prior expectations about the characteristics or benefits of those products and services as a comparative referent (Oliver 1980). The gap between expectation and performance can be positive, when performance exceeds expectations or negative, when performance falls short of expectations (Anderson 1973). This is known as the expectancy disconfirmation model.

Considerable research on public performance evaluation has applied this model, which focuses exclusively on performance in the form of citizen ratings of specific local government services (Miller 1991; Folz 1996). However, expectations that originate from previous experiences, word of mouth, or communications such as advertising and the media (Oliver 1997) have not attracted much interest from researchers in public administration, although some researchers, such as Brown and Coulter (1983), have indicated the importance of appraising citizen expectations in relation to citizen satisfaction with local services.

Even though an increase in expectation level can indicate a decrease in satisfaction or an increase in dissatisfaction, there are two opinions about the role of expectation in satisfaction judgments. Serving as an axle to the evaluation (Deichmann and Lall 2007), people adjust their expectation levels through continuous experiences related to the services or products, and then they have more realistic expectations of what the provider will deliver. Therefore, expectation can be positively related to satisfaction levels (Tversky and Kahneman 1974; Deichmann and Lall 2003). Others suggest that people adjust their perception of the performance to become more consistent with their expectations (Anderson 1973) when they have a psychological conflict about the discrepancy between their expectation and the perceived performance (Sherif and Hovland 1961; Rodriguez, San Mart, and Collado 2006). These two approaches imply that expectation based on prior experiences decreases the difference between expectation and perceived performance through an adjustment or assimilation process.

The disconfirmation model has been used in marketing studies; its application to public services is relatively recent. In the 1970s, marketing studies like those by Anderson (1973) and Oliver (1997) focused on the effect of the disconfirmed expectation on perception of product performance, and in the 1980s the model was used in the SERVQUAL (Service Quality) studies in the private sector (Zeithaml, Berry, and Parasuramn 1988, 1996). Studies in the 1990s used the model in political science (Roch and Poister 2006). Kleyn, Rothmann, and Jackson (2007) tried to determine the 
expectations and satisfaction of both community members and the police in the Rustenburg area of South Africa. Using the survey method, they found that each member of the group had different expectations regarding policing priorities and satisfaction levels (Kleyn, Rothmann, and Jackson 2007). However, their study did not connect expectation levels with satisfaction levels, although they mentioned that expectations for services represent a standard.

Bennett (2007) focused on the differences between what politicians think small and medium-sized enterprises (SMEs) need and what SMEs want. In a survey of the Business Link experience in England, Bennett found that satisfaction with Business Link was the strongest where the SME client was most interested in the service and where the quality expectations were not too demanding. In Bennett's study, expectation was regarded as a starting point to improve service design and delivery processes. In addition, Deichmann and Lall (2007), studying water supply services in India, found that satisfaction increased with absolute improvements in one's own service as well as with the relative quality of service compared to neighbors' services; respondents who were better off than their neighbors tended to show higher satisfaction levels and vice versa.

On the other hand, Van Ryzin (2006) found that expectations had a negative effect on disconfirmation, which is the discrepancy between the anticipated quality of goods or services and the quality that was actually received or experienced, through online survey data in New York. Moreover, the disconfirmation was positively related to satisfaction levels. ${ }^{1}$ An interesting result was that perceived disconfirmation does not fit into the expectancy disconfirmation model, while subtractive disconfirmation (subtracting the expectation level from the service quality level) matches well with the model. In a study based on a statewide survey of Georgia residents regarding three service areas_-trash removal, policing, and education-Roch and Poister (2006) found that higher subjective assessments of service quality were positively related to satisfaction, but high quality service did not indicate the same level of satisfaction.

In prior studies, there have been some discussions regarding concepts of expectation and performance measurement. In this study, such discussions were considered and alternatives were adopted to investigate macro policy satisfaction.

1. In the study, Van Ryzin (2006) used two measurements of disconfirmation: a subtractive measurement, subtracting the expectation levels from the investigated service quality levels, and perceived disconfirmation, using a single-item rating scale. 


\section{Expectation and Trust}

Thompson and Rosa proposed three common types of expectation: (1) ideal expectation, an aspiration, want, or preferred outcome that is based on idealistic beliefs; (2) predicted expectation, a realistic, practical anticipation of outcome based on personal experience, reported experience of others, and other sources such as the media; and (3) normative expectation, based on a subjective, socially endorsed evaluation of what is deserved in a situation (Thompson and Rosa 1995, 131).

Much previous research that applied the expectancy disconfirmation model to public services evaluation focused on predictive expectation (Rodriguez del Bosque, San Mart, and Collado 2006). According to Rust et al. (1999), expectations may be conceptualized as a predictive density for the next transaction; then it is necessary to measure the uncertainty that the customer experiences with respect to the level of services. However, normative expectation would be more appropriate to public service cases, because people usually understand that they have the right to good public services, and diverse rules that control public agents' behavior are designed to benefit the people. Moreover, people have some expectations even for certain public services that they have never received, because the right to respect from public agents is protected by the constitution.

As mentioned above, direct measurement of expectations is not easy, so it is useful to build a proxy: trust that policy participants who play an important role in public service delivery are working appropriately to provide desired services, and trust that policy processes and institutional arrangements are appropriate to provide those services. The quality of a policy and its implementation depend on each participant's appropriate actions throughout the policy process, from identifying policy issues to legitimating policies, and a system that is transparent and reasonable and reflects people's opinions.

While the dominant view has regarded trust in the same light as expectation, recent scholars insist that trust is motivated by unconditional kindness due to social preferences such as altruism and internalized norms (Andreoni and Miller 2002) or due to a warm glow, a selfish motive (Andreoni 1990), rather than being motivated by expectation only (Kramer 1999; Cox 2004). Instead of asking about general trust in government, the present study investigated trust focusing on the role of policy participants and on policy processes and institutional arrangements, controlling altruism which means the willingness to make a donation.

The adequacy of trust as a proxy for measuring expectation is supported by diverse articles about trust. Robinson (1996) defined trust as expectations about the likelihood that another's future actions will be beneficial, favorable, or at least not detrimental to one's interests. Barber (1983) described trust as socially learned and socially con- 
firmed expectations that people have of institutions. Lewis and Weigert suggested a characteristic of trust as the "undertaking of a risky course of action on the confident expectation that all persons involved in the action will act competently and dutifully" (Lewis and Weigert 1985, 971). In other studies, trust has been defined as expectancy about other people and the social systems in which they are embedded (Garfinkel 1963; Luhmann 1988).

Moreover, the two forms of trust described above match the concepts of rule-based trust and role-based trust that Barber mentioned. Role-based trust is derived from the barriers to entry into organizational roles, the training processes, and the various accountability mechanisms intended to ensure role compliance (Kramer 1999). Therefore, high barriers to entry into the government of South Korea and the reward system that ensures accountability can represent their competence. Barber (1983) argued that strong expectations regarding technically competent role performance are typically aligned with roles in organizations as well as expectations that role occupants will fulfill the fiduciary responsibilities and obligations associated with the roles that they occupy. Individuals can adopt a form of presumptive trust on the basis of the knowledge of role relations, even in the absence of personalized knowledge or history of prior interaction (Kramer 1999).

Therefore, this study assumed that trust in policy participants may indicate their loyalty, sense of responsibility, and faithfulness to their roles in making better policies. Also, policy processes are controlled by rules and regulations, not by personal knowledge or personal characteristics. If trust within an organization is about individuals' diffuse expectations and depersonalized beliefs regarding other organizational members, then the understanding of transaction norms and interaction-based routines provides a basis for inferring that others in the organization are likely to behave in a trustworthy fashion (Kramer 1999). Consequently, rule-based trust becomes a potent form of an expectation asset (Knez and Camerer 1994).

\section{CONCEPTUAL MODEL AND RESEARCH METHOD}

\section{Variables in the Conceptual Model}

This study adopted factor analysis to simplify diverse types of trust in policy processes. Institutionalized policy processes mean the policy processes that participants should follow are regulated by rules and laws, from identifying policy issues to evaluating policies (Dye 1998). Institutionalized policy processes exist to preserve values (Young 1977). From a variety of values, three were selected for this study: democracy, 
a process that is organized to reflect people's opinions; transparency, a condition in which information and data related to policy are open to view; and rationality, the basing of policy on reasonable data and logic. After the factor analysis, these three values were categorized to a single factor: trust in the policy process (see table 1).

Related to measurement of performance, researchers have already investigated a gap between perceived service quality and objectively measured service quality (Roch and Poister 2006).

Table 1a. Factor Analysis Results: Trust in Political Actors and Third-Sector Organizations

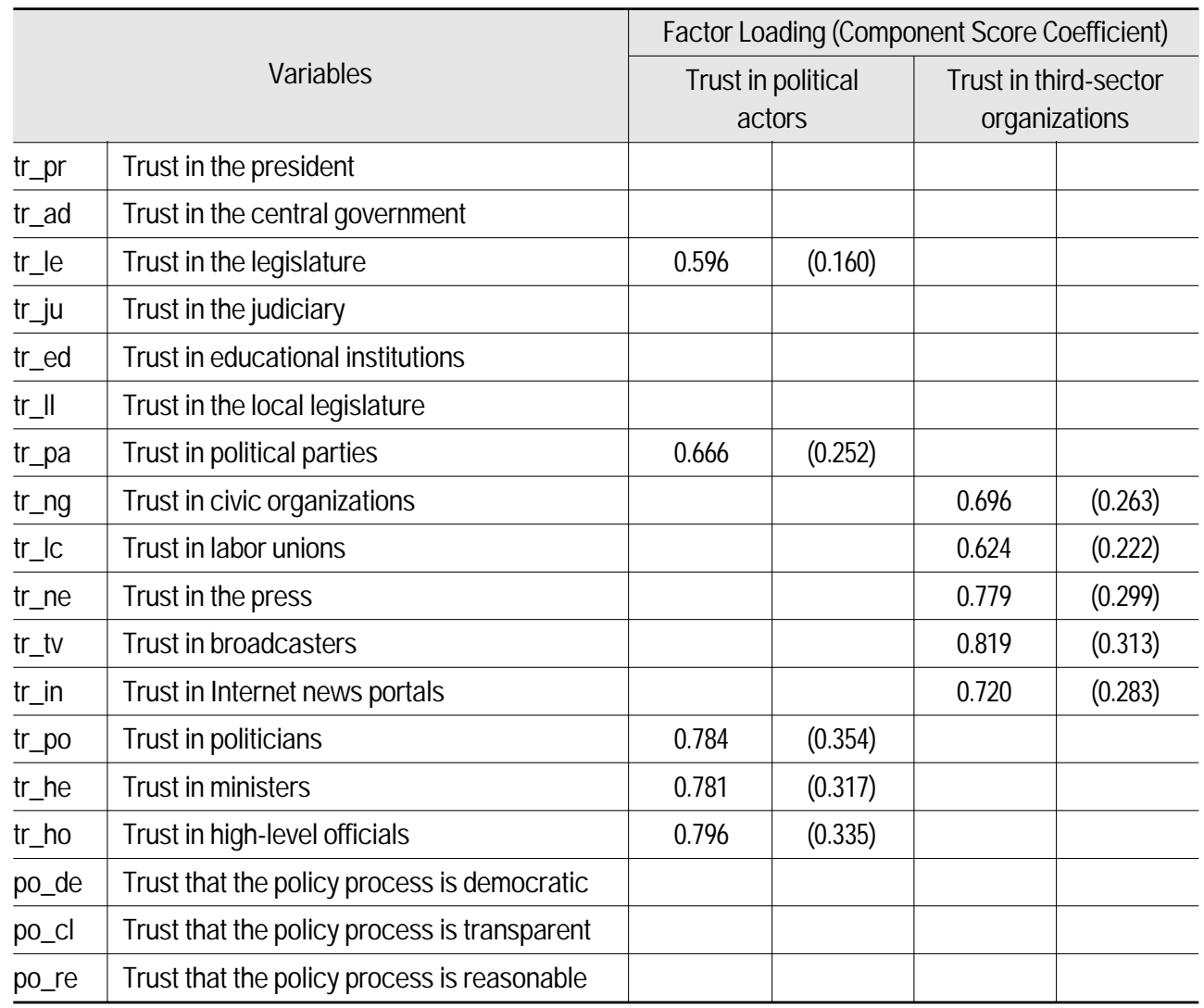

Total explained variance: $64.649 \%$.

Extraction method: principal component analysis.

Rotation method: varimax with Kaiser normalization.

A rotation converged in five iterations. 
Table 1b. Factor Analysis Results: Trust in Central Administrators and the Policy Process

\begin{tabular}{|c|c|c|c|c|c|}
\hline \multirow[b]{3}{*}{ tr_pr } & \multirow[b]{3}{*}{ Trust in the president } & \multicolumn{4}{|c|}{ Factor Loading (Component Score Coefficient) } \\
\hline & & \multicolumn{2}{|c|}{$\begin{array}{l}\text { Trust in central } \\
\text { administrators }\end{array}$} & \multicolumn{2}{|c|}{$\begin{array}{c}\text { Trust in the policy } \\
\text { process }\end{array}$} \\
\hline & & 0.769 & (0.399) & & \\
\hline tr_ad & Trust in the central government & 0.794 & $(0.372)$ & & \\
\hline tr_le & Trust in the legislature & & & & \\
\hline $\operatorname{tr} \_j u$ & Trust in the judiciary & 0.656 & $(0.276)$ & & \\
\hline tr_ed & Trust in educational institutions & 0.599 & $(0.251)$ & & \\
\hline tr_ll & Trust in the local legislature & & & & \\
\hline tr_pa & Trust in political parties & & & & \\
\hline tr_ng & Trust in civic organizations & & & & \\
\hline tr_lc & Trust in labor unions & & & & \\
\hline tr_ne & Trust in the press & & & & \\
\hline tr_tv & Trust in broadcasters & & & & \\
\hline tr_in & Trust in Internet news portals & & & & \\
\hline tr_po & Trust in politicians & & & & \\
\hline tr_he & Trust in ministers & & & & \\
\hline tr_ho & Trust in high-level officials & & & & \\
\hline po_de & Trust that the policy process is democratic & & & 0.811 & $(0.401)$ \\
\hline po_cl & Trust that the policy process is transparent & & & 0.849 & $(0.414)$ \\
\hline po_re & Trust that the policy process is reasonable & & & 0.847 & $(0.414)$ \\
\hline
\end{tabular}

Total explained variance: $64.649 \%$.

Extraction method: principal component analysis.

Rotation method: varimax with Kaiser normalization.

A rotation converged in five iterations.

When applying the disconfirmation model to policy satisfaction, however, there may be two problems in using the subjectively perceived service quality as a variable: conceptual overlapping with satisfaction and inappropriate measurement of the subtractive disconfirmation level. ${ }^{3}$ These problems are related to the level of services. For

2. First, perceived quality is a function of satisfaction (Berry, Zeithaml, and Parasuraman 1983; Parasuraman, Zeithaml, and Berry 2001), and subjectively perceived service quality and satisfaction are all evaluations of service provided; hence, the concepts are overlapping. The subjective perception of service quality is influenced by experience, so it may be that levels of satisfaction with the service already intervened in the perception of quality. Second, related to 
local government services, like policing and water supply, most benefits are tangible and experienced. Some are distributed differently depending on personal characteristics, and people can choose among several available benefits. Therefore, subjectively perceived service quality can be diverse, although local governments provide the identical public service to people.

On the other hand, in macro and abstract public policies, like economic and environmental policies, performance is provided to all people. In addition, it is impossible for one person to choose a policy goal and exclusively possess the result. For instance, a citizen cannot change or select the interest rate that the central government sets. Hence, the perception of performance of macro policies is objective and its variation is relatively small, so the problems caused by subjectively perceived performance can be prevented. Instead, because knowledge and information about such macro policies' performances can vary from person to person, levels of policy understanding should be controlled.

The macro policies examined in this study are national policies; they include policies pertaining to diplomacy and defense, education, the environment, labor, welfare, arts and culture, and health and medical services. Several forms of demographic and personal information were used as control variables: region, size of region, gender, age, political orientation, education level, monthly income, satisfaction with daily life, level of interest in public policy, frequency of public service use, willingness to donate, and policy understanding level (see Equation 1).

Equation 1. Conceptual Model

$\mathrm{SAT}_{\mathrm{P}} \rightarrow \mathrm{f}\left(\mathrm{TR}_{\mathrm{PS}}, \mathrm{TR}_{\mathrm{CA}}, \mathrm{TR}_{\mathrm{TS}}, \mathrm{TR}_{\mathrm{LW}}, \mathrm{EXP}, \mathrm{EXP}_{\mathrm{W}}, \mathrm{UDEP}, \mathrm{POL}, \mathrm{WIL}, \mathrm{INC}\right.$, EDU, SAL, AGE, GEN, INP, REI, RES)

Where:

$\mathrm{P} \quad=$ Macro policies

$\mathrm{SAT}_{\mathrm{P}}=$ Satisfaction level with each policy (seven-scale)

$\mathrm{TR}_{\mathrm{PS}}=$ Trust in policy processes (seven-scale)

$\mathrm{TR}_{\mathrm{CA}}=$ Trust in central administrators (seven-scale)

$\mathrm{TR}_{\mathrm{TS}}=$ Trust in the nonprofit sector (seven-scale)

$\mathrm{TR}_{\mathrm{LW}}=$ Trust in political actors (seven-scale)

measurements, even if a researcher uses the same scale of questions in a survey to gather data, it does not guarantee that the difference between the subjectively perceived quality and expectation of service will indicate the satisfaction level. For instance, in a seven-scale questionnaire, identical scores for perceived quality and expectation do not mean that the perceived quality meets the expectations. This is especially the case when the target service is not concrete enough and overall perception and expectation of quality of service are estimated; because the two estimates do not have common standards, they cannot be compared. 


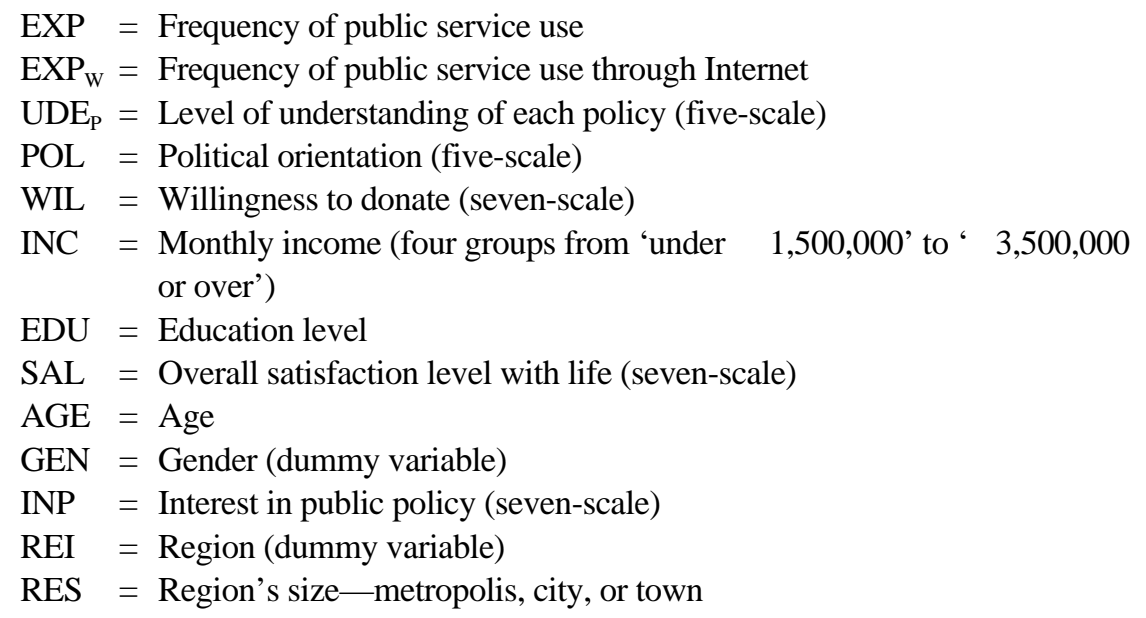

Because policies are the result of political decisions enacted by politicians, respondents may have different levels of satisfaction corresponding to their political orientation, from conservative to progressive. As one of the control variables, policy understanding level (policy literacy) was measured to control the impact of differential knowledge of policies among respondents (see table 2).

Table 2. Demographic Variables

\begin{tabular}{l|r|r||l|r|r}
\hline & Number & \multicolumn{1}{|c||}{$\%$} & & Number & \multicolumn{1}{c}{$\%$} \\
\hline Total & $\mathbf{1 , 1 7 3}$ & $\mathbf{1 0 0 . 0 0}$ & Size of region & $\mathbf{1 , 1 7 3}$ & $\mathbf{1 0 0 . 0 0}$ \\
\hline Male & 580 & 49.30 & M etropolitan & 568 & 48.42 \\
\hline Female & 593 & 50.70 & City & 494 & 42.11 \\
\hline Region & $\mathbf{1 , 1 7 3}$ & $\mathbf{1 0 0 . 0 0}$ & \multicolumn{1}{|c||}{ Town } & 111 & 9.46 \\
\hline Metropolitan & 568 & 48.42 & Age & $\mathbf{1 , 1 7 3}$ & $\mathbf{1 0 0 . 0 0}$ \\
\hline Seoul & 256 & 21.82 & Under 20 & 48 & 4.09 \\
\hline Pusan & 94 & 8.01 & 20 to 29 & 229 & 19.52 \\
\hline Dauge & 58 & 4.94 & 30 to 39 & 286 & 24.38 \\
\hline Incheon & 63 & 5.37 & 40 to 49 & 275 & 23.44 \\
\hline Gwangju & 34 & 2.90 & 50 to 59 & 147 & 12.53 \\
\hline Daejeone & 35 & 2.98 & 60 to 69 & 146 & 12.45 \\
\hline Ulsan & 28 & 2.39 & 70 and older & 42 & 3.58 \\
\hline State & $\mathbf{6 0 5}$ & $\mathbf{5 1 . 5 8}$ & Political orientation & $\mathbf{1 , 1 7 3}$ & $\mathbf{1 0 0 . 0 0}$ \\
\hline Gyeonggi-do & 253 & 21.57 & Very progressive & 54 & 4.60 \\
\hline Gangwon-do & 36 & 3.07 & Somew hat progressive & 244 & 20.80 \\
\hline
\end{tabular}




\begin{tabular}{l|r|r||l|r|r}
\hline & Number & \multicolumn{1}{|c||}{$\%$} & & Number & \multicolumn{1}{c}{$\%$} \\
\hline Chungbuk & 35 & 2.98 & Neutral & 516 & 43.99 \\
\hline Chungnam & 49 & 4.18 & Somewhat conservative & 307 & 26.17 \\
\hline J eongbuk & 45 & 3.84 & Very conservative & 52 & 4.43 \\
\hline J eongnam & 49 & 4.18 & Education level & $\mathbf{1 , 1 7 3}$ & 100.00 \\
\hline Gyeongbuk & 62 & 5.29 & M iddle school or less & 246 & 20.97 \\
\hline Gyeongnam & 76 & 6.48 & High school graduate & 482 & 41.09 \\
\hline Income & 1,173 & 100.00 & University or more & 445 & 37.94 \\
\hline under 149 & 295 & 25.15 & Satisfaction with life & 1,173 & 100.00 \\
\hline 150 to 250 & 353 & 30.09 & Completely dissatisfied & 95 & 8.10 \\
\hline 250 to 350 & 324 & 27.62 & Somewhat dissatisfied & 354 & 30.18 \\
\hline 350 or more & 201 & 17.14 & Neutral & 515 & 43.90 \\
\hline unit: $\backslash 10,000$ & & & Somewhat satisfied & 202 & 17.22 \\
\hline
\end{tabular}

Policy literacy means the ability to recognize and analyze knowledge and information regarding a certain policy, as well as the ability to utilize the policy knowledge and information effectively (Lo Bianco 2001). Policy understanding levels influence participation and result in unequal distribution of policy benefits. Schlozman, Verba, and Brady (1999) also argued that the policy understanding gap among people is connected to the differential levels of participation in policy processes and of opportunities that participants enjoy to proclaim their own opinions.

The quantity of public service use experience was measured by the frequency of use in a week, a month, and a year. Factor analysis suggested that central and local government experience with public service was similar, so they were categorized according to frequency of public service use. South Korea has developed an electronic system in which people can receive public services through the Internet, and the frequency of that use was also measured.

\section{Survey Method and Data Analysis}

The data used in this study were obtained from the "Citizen Perception Survey (2007)," conducted from December 2006 to January 2007 by the Knowledge Center for Public Administration and Policy at Seoul National University. A total of 1,200 people responded. ${ }^{3}$ Samples were selected randomly with regard to population distrib-

3. The survey questionnaire asked about citizens' perceptions on issues including public policies, 
ution for each of the following regions: Seoul, Inchon, Kyonggi, Kangwon, Daejeon, Chungchong, Gwangju, Jeonra, Daegu, Kyongbuk, Pusan, Ulsan, and Kyungnam. Of the respondents, 48 percent lived in large cities, 42.3 percent in small cities, and 9.7 percent in rural areas. Males made up 50.7 percent of the sample and females 49.3 percent (see table 2). The questionnaire consisted of 135 questions, most of which presented closed-ended response choices on a seven-point scale.

Table 3 summarizes the descriptive statistics on satisfaction and understanding level for each policy. To perform a multivariate regression analysis, SPSS 12.0 was used. Factor analysis was implemented with principal component analysis and varimax rotation with Kaiser normalization. Through the analysis, only variables for which factor loading was over 0.5 were selected, and each component was calculated by using each variable's component score coefficient. The VIF (variance inflation factor) values were less than 2.502 in all variables of all equations; multicollinearity was not serious. From the scatter plots of residual against standardized predicted values of the dependent variable, there was no serious violation of the homoscedasticity assumption, one of the Gauss-Markov assumptions that is necessary to an adequate multiple regression analysis (Wooldridge 2000). However, the plots' shapes and R square values, which are very low (from 0.207 to 0.256 ), indicated that more independent variables are needed.

Table 3. Policy Understanding Level and Satisfaction Level

\begin{tabular}{|c|c|c|c|c|}
\hline \multirow[t]{2}{*}{ Policy } & \multicolumn{2}{|c|}{$\begin{array}{l}\text { Policy understanding } \\
1=\text { do not understand at all } \\
7=\text { understand very well }\end{array}$} & \multicolumn{2}{|c|}{$\begin{array}{l}\text { Policy satisfaction } \\
1=\text { completely dissatisfied } \\
7=\text { completely satisfied }\end{array}$} \\
\hline & Mean & SD & Mean & SD \\
\hline Diplomacy, defense, and unification & 3.470 & 1.441 & 2.975 & 1.330 \\
\hline Education & 3.676 & 1.509 & 2.720 & 1.261 \\
\hline Health and medical services & 3.348 & 1.392 & 3.320 & 1.302 \\
\hline Welfare & 3.737 & 1.395 & 3.308 & 1.366 \\
\hline Environment & 3.539 & 1.403 & 3.266 & 1.274 \\
\hline Arts and culture & 3.349 & 1.392 & 3.408 & 1.224 \\
\hline Labor & 3.326 & 1.459 & 2.956 & 1.238 \\
\hline
\end{tabular}

administrative processes, experience with public services, participation in regional communities, trust, social order as regulated by law, and respondents' personal information. Of the 1,200 respondents, 27 were excluded from statistical analysis due to missing values because they chose the "no answer" option to one or more questions. 


\section{THE ANTECEDENTS OF POLICY SATISFACTION}

\section{Results of the Regression Analysis}

The results show, first, that expectation that is measured by trust in policy participants is a significant factor affecting policy satisfaction level. Except for the case of trust in political actors, other independent variables were significant to all macro policies (see table 4).

Central administrators in this study included the central government, the president, the judiciary, and the educational institutions. The major roles of the president and the central government are to make policies and the regulations that are necessary to

Table 4a. Results of the Regression Analysis: Diplomacy, Defense, and Unification Policy and Education Policy

\begin{tabular}{l|c|c||c|c}
\hline \multirow{2}{*}{} & \multicolumn{2}{|c||}{$\begin{array}{c}\text { Diplomacy, defense, } \\
\text { and unification policy }\end{array}$} & \multicolumn{2}{c}{ Education policy } \\
\cline { 2 - 5 } & B & Sig. & B & Sig. \\
\hline Constant & $0.781^{*}$ & 0.065 & 0.364 & 0.367 \\
\hline Monthly income & -0.017 & 0.316 & $-0.050^{* * *}$ & 0.002 \\
\hline Oducation level & -0.065 & 0.255 & -0.084 & 0.152 \\
\hline Political orientation & $0.071^{*}$ & 0.092 & $0.151^{* * *}$ & 0.000 \\
\hline Interest in public policy & $-0.094^{* *}$ & 0.018 & 0.016 & 0.668 \\
\hline Age & $0.041^{*}$ & 0.098 & 0.020 & 0.391 \\
\hline Gender & 0.001 & 0.672 & 0.003 & 0.286 \\
\hline Trust in policy processes & 0.059 & 0.411 & 0.052 & 0.441 \\
\hline Trust in central administrators & $0.157^{* * *}$ & 0.000 & $0.134^{* * *}$ & 0.000 \\
\hline Trust in third-sector organizations & $0.266^{* * *}$ & 0.000 & $0.150^{* * *}$ & 0.000 \\
\hline Trust in political actors & $0.077^{* *}$ & 0.023 & $0.101^{* * *}$ & 0.002 \\
\hline Experience with public service & $0.058^{*}$ & 0.093 & $0.155^{* * *}$ & 0.000 \\
\hline Experience with public service through Internet & 0.015 & 0.376 & 0.003 & 0.839 \\
\hline Understanding level for each policy & $0.107^{* * *}$ & 0.000 & $0.081^{* * *}$ & 0.001 \\
\hline Willingness to donate & 0.003 & 0.879 & -0.028 & 0.179 \\
\hline F & $13.263^{* * *}$ & & $12.500^{* * *}$ & \\
\hline Adjusted R square & 0.233 & & 0.222 & \\
\hline Stisticas signicance: 0.1* & & & &
\end{tabular}

Statistical significance: $* 0.1 ; * 0.05 ; * * * 0.01$ 
Table 4b. Results of the Regression Analysis: Health and M edical Services Policy and Welfare Policy

\begin{tabular}{l|c|c||c|c}
\hline \multirow{2}{*}{} & \multicolumn{2}{|c||}{$\begin{array}{c}\text { Health and medical } \\
\text { services policy }\end{array}$} & \multicolumn{2}{c}{ Welfare policy } \\
\cline { 2 - 5 } & B & Sig. & B & Sig. \\
\hline Constant & $0.901^{* *}$ & 0.031 & 0.222 & 0.605 \\
\hline M onthly income & -0.030 & 0.077 & -0.018 & 0.310 \\
\hline Education level & -0.089 & 0.116 & -0.058 & 0.315 \\
\hline Overall satisfaction with life & $0.077^{*}$ & 0.068 & 0.068 & 0.118 \\
\hline Political orientation & 0.018 & 0.696 & 0.038 & 0.345 \\
\hline Interest in public policy & $0.050^{* *}$ & 0.040 & $0.057^{* *}$ & 0.025 \\
\hline Age & -0.001 & 0.871 & 0.005 & 0.151 \\
\hline Gender & $0.146^{* *}$ & 0.032 & 0.070 & 0.335 \\
\hline Trust in policy processes & $0.127^{* * *}$ & 0.000 & $0.152^{* * *}$ & 0.000 \\
\hline Trust in central administrators & $0.165^{* * *}$ & 0.000 & $0.144^{* * *}$ & 0.000 \\
\hline Trust in third-sector organizations & $0.096^{* * *}$ & 0.004 & $0.121^{* * *}$ & 0.001 \\
\hline Trust in political actors & $0.089^{* * *}$ & 0.009 & $0.084^{* *}$ & 0.018 \\
\hline Experience with public service & 0.009 & 0.485 & 0.019 & 0.155 \\
\hline Experience with public service through Internet & -0.01 & 0.551 & -0.012 & 0.489 \\
\hline Understanding level for each policy & $0.190^{* * *}$ & 0.000 & $0.221^{* * *}$ & 0.000 \\
\hline Willingness to donate & 0.033 & 0.121 & 0.028 & 0.201 \\
\hline F & $12.411^{* * *}$ & & $14.129^{* * *}$ & \\
\hline Adjusted R square & 0.220 & & 0.245 & \\
\hline Statstica signicance* & & & & \\
\hline
\end{tabular}

Statistical significance: $* 0.1 ; * * 0.05 ; * * * 0.01$

implement the policies. While in most cases practical and concrete public services are provided by local agents, principles and goals are established by the central administration and the president. The judiciary complements policy implementation by resolving conflicts that arise from complicated interests related to public policy. Therefore, trust in central administrators means an expectation that they will make and implement policies that people desire.

In this study, political actors included political parties, the legislature, politicians, ministers, and high-level officials. They are elected by the people or employed in government organizations; although ministers, the heads of the administrative departments, are appointed by the president, appointments must be confirmed by the national assembly, and the president considers political interests when making appointments. Legislators pass laws that can control the activities of administrators and oversee the 
Table 4c. Results of the Regression Analysis: Environmental Policy and Arts and Culture Policy

\begin{tabular}{l|c|c||c|c}
\hline \multirow{2}{*}{} & \multicolumn{2}{|c||}{ Environment policy } & \multicolumn{2}{c}{ Arts and culture policy } \\
\cline { 2 - 5 } & B & Sig. & B & Sig. \\
\hline Constant & 0.714 & 0.085 & $0.798^{* *}$ & 0.042 \\
\hline M onthly income & -0.009 & 0.577 & -0.024 & 0.141 \\
\hline Education level & -0.043 & 0.437 & 0.027 & 0.609 \\
\hline Overall satisfaction with life & $0.075^{*}$ & 0.074 & $0.143^{* * *}$ & 0.000 \\
\hline Political orientation & $0.048^{* *}$ & 0.218 & 0.029 & 0.441 \\
\hline Interest in public policy & 0.0003 & 0.991 & 0.015 & 0.498 \\
\hline Gender & $0.007^{* *}$ & 0.033 & 0.002 & 0.518 \\
\hline Trust in policy processes & $0.133^{*}$ & 0.052 & 0.057 & 0.386 \\
\hline Trust in central administrators & $0.127 * * *$ & 0.000 & $0.091^{* * *}$ & 0.000 \\
\hline Trust in third-sector organizations & $0.121 * * *$ & 0.001 & $0.168^{* * *}$ & 0.000 \\
\hline Trust in political actors & $0.126^{* * *}$ & 0.000 & $0.175^{* * *}$ & 0.000 \\
\hline Experience with public service & 0.051 & 0.133 & -0.015 & 0.650 \\
\hline Experience with public service through Internet & -0.004 & 0.792 & -0.013 & 0.417 \\
\hline Understanding level for each policy & $0.179^{* * *}$ & 0.000 & $0.231^{* * *}$ & 0.000 \\
\hline Willingness to donate & 0.016 & 0.450 & -0.001 & 0.978 \\
\hline F & $10.863^{* * *}$ & & $12.866^{* * *}$ & \\
\hline Adjusted R square & 0.196 & 0.227 & & \\
\hline Staistical & & & &
\end{tabular}

Statistical significance: $* 0.1 ; * * 0.05 ; * * * 0.01$

policy process. They review draft budgets submitted by administrators and can cut the budgets needed to implement policies. With strong authority over the activities of administrators, their basic role is, theoretically, to represent the people's desires and concerns. Analysis of the results of this study showed that expectation of political actors is not significant to satisfaction with environment policy and arts and culture policy.

The nonprofit sector includes labor unions, civil organizations, the press, broadcasters, and Internet news portals. Their common characteristic is that each organization represents the people or its own members; the nonprofit sector's role is that of a mediator between the organized economic interests of private companies and labor and the political interests of state agencies and their constituencies (Lehmbruch and Schmitter 1982). Although civil organizations' efforts complement government activities, they are independent of the government. Expectation of the nonprofit sector is significant to satisfaction with all macro policies. 
Table 4d. Results of the Regression Analysis: Labor Policy

\begin{tabular}{l|c|c}
\hline \multirow{2}{*}{ Constant } & \multicolumn{2}{|c}{ Labor policy } \\
\cline { 2 - 3 } M onthly income & B & Sig. \\
\hline Education level & 0.210 & 0.592 \\
\hline Overall satisfaction with life & -0.010 & 0.513 \\
\hline Political orientation & 0.042 & 0.420 \\
\hline Interest in public policy & 0.061 & 0.118 \\
\hline Age & 0.037 & 0.312 \\
\hline Gender & 0.002 & 0.914 \\
\hline Trust in policy processes & 0.001 & 0.639 \\
\hline Trust in central administrators & $0.182^{* * *}$ & 0.006 \\
\hline Trust in third-sector organizations & $0.124^{* * *}$ & 0.000 \\
\hline Trust in political actors & $0.177^{* * *}$ & 0.000 \\
\hline Experience with public service & $0.157^{* * *}$ & 0.000 \\
\hline Experience with public service through Internet & $0.114^{* * *}$ & 0.000 \\
\hline Understanding level for each policy & -0.002 & 0.894 \\
\hline Willingness to donate & -0.003 & 0.849 \\
\hline F & $0.139^{* * *}$ & 0.000 \\
\hline Adjusted R square & -0.013 & 0.513 \\
\hline Statical signicance* $01 * * 05 ; * * 01$ & $14.000^{* * *}$ & \\
\hline
\end{tabular}

Statistical significance: $* 0.1 ; * * 0.05 ; * * * 0.01$

Trust that the policy process is transparent and rational and represents people's opinions is categorized as one factor. Actually, the policy process is controlled by institutional arrangements that are appropriate to provide services desired by people, so it cannot be easily changed and misused for self-interests. Therefore, policy processes are made to preserve the benefits that people should receive adequately and fairly. The expectation that policy processes are transparent, rational, and democratic is significant to satisfaction with all macro policies.

\section{Discussion and Implications}

Each independent variable has a positive relationship with policy satisfaction. According to the expectancy disconfirmation model, high expectation about a performance would increase the discrepancy between expectation level and performance, so satisfaction would decrease or dissatisfaction would increase. Therefore, the disconfir- 
mation model does not fit these results.

Though there are some alternative interpretations, they may be not appropriate to explain the present study's results. According to Deichmann and Lall (2007), people adjust their expectations based on experience, and their expectations become more realistically related to policy performance. However, the quantity of experience with public services, which is used as a control variable in this study, is not significant to satisfaction; hence, such an interpretation does not seem suitable. An alternative interpretation is that people's perceptions about performance are adjusted to be more consistent with their expectations (Anderson 1973).

As mentioned above, such adjusted perception of performance overlaps with satisfaction. Therefore, although this study found that expectation is a significant factor affecting policy satisfaction, it is hard to conclude that the disconfirmation model is suitable to public policy cases.

There are diverse possible explanations for this failure of the model developed in marketing studies to apply to satisfaction with public policies, even though they cannot be tested with this study's results. Unlike in private market conditions, the government is a monopolistic provider of public policies, and the people must make their choice from these policies. As long as the people are passive consumers of public policies, their expectation may not have negative influences on their satisfaction, because they are likely to receive public services from the same providers in future. Another possible explanation concerns the policy providers, since most of them are elected or serve as representatives of the public. People who voted for the policy makers, or otherwise took part in policy making, are likely to feel some responsibility for their performance. Partly for the sake of self-justification in light of those responsibilities, they may decrease their dissatisfaction or increase their satisfaction.

Predictive expectation, which is often the focus of marketing studies, is based on prior experiences. Although both the quantity and the diversity of public services that people experience should be considered together, the results of this study regarding experiences indicate that predictive expectation is not relevant to public policy cases. Two other types of expectation-normative expectation and ideal expectation-are more relevant. It was not tested whether respondents considered ideal policies when they responded to the survey, so it is hard to say whether ideal expectation is more appropriate to explain this study's results than the other two types of expectation.

On the other hand, the normative expectation that people expect what they have to be received is estimated by using a proxy variable, and it appears to have significant influence on policy satisfaction. Expectation about the quality of services that people will receive is measured by trust that policy participants and institutional arrangements will provide those services. People already recognize that the policy process is gov- 
erned by rules and regulations that are supposed to make it responsive to their lawful demands, and that they have the right to be treated equitably.

Although the expectancy disconfirmation model did not fit public policy cases in this study, that does not imply that expectation is useless as an antecedent of satisfaction. Conversely, expectation is a statistically significant factor to understand satisfaction; with a given quality of performance, expectations of the service provider and process influence the level of satisfaction.

This influence is positive. With the same public policy or service, people in a region with relatively high trust in the local government's service providers and process are likely to be more satisfied than people in a region with low trust. On the other hand, a local government with relatively inferior public performance can get a generous appraisal from people if they have had strong trust in the service providers. This implies that performance as well as trust in service providers and processes should be considered important to increase people's public service satisfaction. Hence, it is necessary to consider strategies that can increase people's trust and expectation.

\section{CONCLUSION AND SUGGESTIONS FOR FUTURE RESEARCH}

Much prior research has focused on the performance of public policies such as the New Public Management, and a number of discussions have applied marketing and management models to the public sector. This study attempted to apply the expectancy disconfirmation model of customer satisfaction, derived from the private sector, to macro policy satisfaction. This attempt failed; the model's implication that higher expectations induce lower satisfaction did not fit when applied to macro policy cases, in which high expectations have a significant positive influence on satisfaction. Moreover, the type of expectation that is the focus of marketing studies, predictive expectation, appears not to be applicable to public policy cases; the quantity of prior experiences as a basis of predictive expectation is not significant to policy satisfaction.

Even though the current study suggested important policy implications, there are certain limitations. First, although its purpose was to measure the influence of expectation on policy satisfaction, most equations that it analyzed had very low R-squared values. Though diverse control variables for individual environment factors were used, most of them were not significant, and other variables should be considered. This problem can be solved by means of more extensive review of the literature on policy evaluation.

Second, policy satisfaction is not a robust concept. Other studies have used it with diverse sub-values: accessibility, ease of use, punctuality, equity, cost and benefit, and 
so on. Due to the limitations of the data, this study measured policy satisfaction by a single item; consequently, the measure can not be entirely accurate. Third, survey questions regarding expectation and performance should be more specific and well organized.

This study used secondary data and was bound by those data's limitations. Respondents' answers to survey questions about expectation and performance may have depended on their satisfaction levels. Questions regarding expectations should be asked before the services have been implemented, and questions regarding satisfaction should be asked immediately after the services have been implemented, using a pretest or the panel data analysis method. There is room for further study regarding the relationship between policy satisfaction and expectations.

\section{REFERENCES}

Anderson, R. E. 1973. Consumer dissatisfaction: The effect of disconfirmed expectancy on perceived product performance. Journal of Marketing Research 10 (1): 38-44.

Andreoni, J. 1990. "Impure altruism and donations to public goods: A theory of warm-glow giving?" Economic Journal 100: 464-77.

Andreoni, J., and J. Miller. 2002. Giving according to GARP: An experimental test of the consistency of preferences for altruism. Econometrica 70: 737-53.

Barber, B. 1983. The logic and limits of trust. New Brunswick, NJ: Rutgers University Press.

Bennett, R. J. 2007. Expectations-based evaluation of SME advice and consultancy: An example of business link services. Journal of Small Business and Enterprise Development 14 (3): 435.

Berry, L. L., V. A. Zeithaml, and A. Parasuraman. 1983. Quality counts in services, too. Journal of Marketing 9: 20.

Brown, K., and P. B. Coulter. 1983. Subjective and objective measures of police service delivery. Public Administration Review 43 (1): 50-58.

Citizen Perception Survey. 2007. Administration service monitoring. Seoul: Knowledge Center for Public Administration and Policy, Seoul National University.

Cox, J. C. 2004. How to identify trust and reciprocity. Games and Economic Behavior 46: $260-81$.

Deichmann, U., and S. V. Lall. 2003. Are you satisfied? Citizen feedback and delivery of urban services. World Bank Policy Research Working Paper No. 3070.

Deichmann, U., and S. V. Lall. 2007. Citizen feedback and delivery of urban services. World Development 35 (4): 649-62. 
Dye, T. R. 1998. Understanding public policy. Englewood Cliffs, NJ: Prentice Hall. Folz, D. H. 1996. Survey research for public administration. Thousand Oaks, CA: Sage Publications.

Garfinkel, H. 1963. A conception of, and experiments with trust as a condition of stable concerted actions. In Motivation and social interaction: Cognitive determinants, ed. O. J. Harvey, 81-93. New York: Ronald.

Kleyn, E., S. Rothmann, and L. T. B. Jackson. 2007. Expectations of and satisfaction with the South African police service in the Rustenburg area. SA Journal of Industrial Psychology 30 (1): 37-45.

Knez, M., and C. Camerer. 1994. Creating expectational assets in the laboratory: Coordination in weakest-link games. Strategic Management Journal 15 (8): 101-119.

Kramer, R. M. 1999. Trust and distrust in organizations: Emerging perspectives, enduring questions. Annual Review of Psychology 50 (1): 569.

Lehmbruch, G., and P. C. Schmitter. 1982. Patterns of corporatist policy-making. London: Sage Publications.

Lewis, J. D., and A. Weigert. 1985. Trust as a social reality. Social Forces 63:967-85.

Lo Bianco, J. 2001. Policy literacy. Language and Education 15 (2): 212-27.

Luhmann, N. 1988. Familiarity, confidence, trust: Problems and alternatives. In Trust: Making and breaking cooperative relations, ed. D. Gambetta, 94-108. Cambridge, MA: Oxford University Press.

Miller, T. I. 1991. Citizen surveys: How to do them, how to use them, what they mean. Washington, DC: International City/County Management Association.

Oliver, R. L. 1980. A cognitive model for the antecedents and consequences of satisfaction. Journal of Marketing Research 17 (4): 460-69.

Oliver, R. L. 1997. Satisfaction: A behavioral perspective on the consumer. New York: McGraw Hill.

Parasuraman, A., V. A. Zeithaml, and L. L. Berry. 2001. A multiple-item scale for measuring consumer perceptions of service quality. Marketing: Critical Perspectives on Business and Management 64 (1): 12-40.

Park, Soon Ae, and Hwang, Duk Yun. 2009. The Impact of Social Capital on Satisfaction with National Policy. Korean Journal of Policy Studies 23 (2): 201-23.

Robinson, S. L. 1996. Trust and breach of the psychological contract. Administrative Science Quarterly 41 (4): 574-99.

Roch, C. H., and T. H. Poister. 2006. Citizens, accountability, and service satisfaction: The influence of expectations. Urban Affairs Review 41 (3): 292.

Rodriguez del Bosque, I. A., H. San Mart, and J. Collado. 2006. The role of expectations in the consumer satisfaction formation process: Empirical evidence in the 
travel agency sector. Tourism Management 27 (3): 410-19.

Rust, R. T., J. J. Inman, J. Jia, and A. Zahorik. 1999. What you don't know about customer-perceived quality: The role of customer expectation distributions. Marketing Science 18 (1): 77-92.

Schlozman, K. L., S. Verba, and H. E. Brady. 1999. Civic participation and the equality problem. In Civic engagement in American democracy, ed. T. Skocpol and M. P. Fiorina, 427-59. Washington, DC: Brookings Institution Press.

Sherif, M., and C. I. Hovland. 1961. Social judgment: Assimilation and contrast effects in communication and attitude change. New Haven, CT: Yale University Press.

Thompson, A. G. H., and R. Sunol. 1995. Expectation as determinants of patient satisfaction: Concepts, theory and evidence. International Journal for Quality in Health Care 7 (2): 127-41.

Tversky, A., and D. Kahneman. 1974. Judgment under uncertainty: Heuristics and biases. Science 185 (4157): 1124-31.

Van Ryzin, G. G. 2006. Testing the expectancy disconfirmation model of citizen satisfaction with local government. Journal of Public Administration Research and Theory 16 (4): 599.

Wooldridge, J. M. 2000. Introductory econometrics. Cincinnati, OH: South-Western College Publishing.

Young, K. 1977. "Values" in the policy process. Policy \& Politics 5 (3): 1-22.

Zeithaml, V. A., L. L. Berry, and A. Parasuraman. 1988. Communication and control processes in the delivery of service quality. Journal of Marketing 52 (2): 35-48.

Zeithaml, V. A., L. L. Berry, and A. Parasuraman. 1996. The behavioral consequences of service quality. Journal of Marketing 60:31-46. 